\title{
The impact of different government units in the regulation of the workplace environment
}

\author{
MICHAEL L. MARLOW \\ The George Washington University
}

\begin{abstract}
This study examines the issue of whether or not state and federal job safety agencies provide the same levels of public output. Tests are conducted on the hypothesis that state takeover of regulation from the federal program serves to reduce the costs of firms. These costs are comprised of two components: the penalties for noncompliance and the uncertainty costs of regulation. The public policy implication that is drawn from these tests is that it matters to firms which government unit regulates them.
\end{abstract}

The Occupatioanal Safety and Health (OSH) Act was enacted in 1970 to provide uniform job safety regulation for the nation. ${ }^{1}$ Prior to the OSH Act, regulation was the sole responsibility of states. Some states carried no safety laws until recently; the first job safety statute in Texas was enacted in $1967 .^{2}$ The OSH.Act does not prevent any state from asserting jurisdiction under state law when that state is '... at least as effective in providing safe and healthful employment and places of employment as the standards promulgated ...' under the OSH Act. ${ }^{3}$ Therefore, states have two options to choose from: Leave regulation to the Occupational Safety and Health Administration (OSHA) or provide its own program of regulation.

States which operate their own programs must first seek approval from OSHA. OSHA pays 50 percent of the operating costs of approved state programs. Once programs are approved, OSHA retains discretionary enforcement authority for three years while it monitors the performance of states. OSHA may then reject programs during this period and the federal program would continue. There are 21 states which operate their own programs. 5

This paper presents a model which explains why certain states elect to operate their own programs. Tests are conducted on the hypothesis that state takeover of regulation from the federal program serves to reduce the costs of firms. These costs are comprised of two components: the penalties for noncompliance and the uncertainty costs of regulation. The policy implications of

* This paper has benefitted from the construcive comments of Joseph Cordes and Harry Watson. 
these tests offer insights into the issue of whether or not different government units provide the same levels of public output.

\section{Model of state programming}

The rationale for inclusion of state programming in the OSH Act is to provide states with the choice between minimum regulation by OSHA or more regulation through their own programs. This is consistent with one of the goals of the $\mathrm{OSH}$ Act which is to specify minimum safety requirements for the workplaces of the nation. In order to conclude that state programming provides the same level of output as federal, it is necessary to understand what incentives exist for states to elect the option of regulating their own work environments. One rationale for states to operate their own programs may be that firms evaluate the regulatory environments of states. ${ }^{6}$ For example, if there exist two locations where a firm might locate and be equally as well off, except for job safety regulatory programs, then it would choose that location which offers the lower costs of regulation. This is consistent with the notion that the potential entrants of an area purchase environmental, access, physical, and public output characteristics. In this case, the cost imposed upon firms by regulation is one part of public output characteristics and partly determines decisions to locate in an area or not.

States may respond to this concern of firms. By operating their own programs states may be better able to control their public output characteristics. There exist at least two possible ways to decrease the costs of regulation to firms when states elect to operate their own job safety programs. One way is to offer firms less stringent enforcement programs than under federal programming. This could take the form of lower probabilities of inspections and lower penalties for observed cases of noncompliance relative to the federal program. The other is to decrease the uncertainty associated with future regulation by offering firms more stable regulatory environments than under federal programming. This is one means of lowering the costs associated with regulation to firms. If state takeover of job safety regulation serves to decrease the regulatory costs of firms, then the costs of paying for 50 percent of the operating costs of the regulatory program may be outweighed by the benefits of increased firm migration, decreased firm outmigration, and the resulting increases in jobs, tax revenues, and penalty revenues to states. ${ }^{7}$ For those states whose benefits are not expected to outweigh the costs of takeover, this model suggests that it is not in their interests to operate their own programs. ${ }^{8}$

Four hypotheses on the differences between federal and state programming are derived from this model of state programming. First, state programs exert lower costs of noncompliance on firms than do federal programs. Second, the characteristics of state enforcement programs are more variable than those of 
federal programs since states which operate their own programs seek to individually control their regulatory environments to suit the needs of their firms. Third, state programs offer firms a more stable and certain regulatory environment over time than do federal programs. Fourth, there is migration by firms to states with state programming in response to the expected differences in the regulatory environments of federal and state programs. The first three hypotheses are tested in this paper while testing of the fourth hypothesis is left for future research in this area.

\section{Tests of differences between federal and state programming}

Before tests of differences between programming are conducted, it is necessary to determine whether or not there exists significant differences in levels of occupational risk between federal and state programming jurisdictions. Jurisdiction is of two types - 29 states and the District of Columbia which operate under federal programming and the 21 states under state programming. This determination is crucial to the testing of the three above hypotheses because it is necessary to evaluate only the differences in enforcement programs and not the differences in risk in the jurisdictions. For example, higher penalties in federal programming may be only the result of higher levels of risk in the states under federal programming relative to states under state programming. State risk levels are determined by many factors. These factors include the characteristics of job safety programs and the industrial composition of states. State standardized occupational injury and illness incidence rates are used to measure risk. ${ }^{9}$ Tests for significant differences between the means and variances of the jurisdictional levels of risk show that at the 95 percent level of confidence the null hypothesis that the average risk in the two jurisdictions are not significantly different from each other cannot be rejected. Failure to reject the null hypothesis indicates that the workplace environments of the two jurisdictions were similar during 1974, 1975, and 1976, and that the tests which are conducted below offer useful information on the differences between federal and state programming. ${ }^{10}$

\subsection{Test of hypothesis 3: Differences between means}

Hypothesis 1 is that state programs exert lower costs of noncompliance on firms than do federal programs. Four parameters are chosen to represent jurisdictional enforcement programs. ${ }^{11}$ The probability of inspection, $P$, is the number of first-time inspections in a given year over the number of firms for each state. Average penalties for serious and nonserious violations, $F_{1}$ and $F_{2}$, respectively, are determined by dividing total dollar penalties by the number of such violations for each state in appropriate years. A serious violation is 
Table 1. Means of enforcement parameters by state and federal jurisdiction

\begin{tabular}{lrrr}
\hline Parameter & 1975 & 1976 & 1977 \\
\hline Probability of inspection, P & & & \\
$\quad$ State & .078 & .075 & .066 \\
$\quad$ Federal & .023 & .024 & .015 \\
& & & \\
Average serious fine, $F_{1}$ & & & \\
$\quad$ State & $\$ 488.75$ & $\$ 613.54$ & $\$ 421.58$ \\
$\quad$ Federal & 590.62 & 627.89 & 370.82 \\
& & & \\
Average nonserious fine, F & & & \\
$\quad$ State & $\$ 206.57$ & $\$ 50.12$ & $\$ 77.67$ \\
$\quad$ Federal & 44.56 & 54.60 & 60.86 \\
$\quad$ & & & .225 \\
Violations per firm, V & .263 & .263 & .066 \\
$\quad$ State & .123 & .136 & \\
$\quad$ Federal & & & \\
\hline
\end{tabular}

considered by OSHA to carry a significant probability that death or serious harm could result, while a nonserious violation is one that probably would not cause serious injury. ${ }^{12}$ The fourth parameter, $V$, is the total number of detected violations per firm and serves to measure the intensity of inspections in each state. Table 1 displays the means of these enforcement parameters for fiscal years 1975, 1976, and 1977.

Table 2 displays the test statistics for the null hypothesis that there exists no significant difference between the means of enforcement parameters in the two jurisdictions between fiscal years 1975 to 1977 . The $t$-statistics are the numbers displayed for means, $u$. For both $P$ and $V$ the state average is always significantly higher than the federal average. For $F_{1}$ and $F_{2}$ there exist no significant differences between state and federal values except for $F_{1}$ in 1975 . In this year the federal average for $F_{1}$ is significantly higher than the state. These results suggest that state programming offers firms a higher level of nonmonetary enforcement than under federal programming. The policy implication is that state programming offers states a means of providing additional regulation over what is provided by OSHA.

A possible explanation for the finding of significant differences between the means of the nonmonetary but not monetary enforcement parameters is that administrators of state programs operate under different incentives than the administrators of the federal program. State administrators may feel a need to justify the existence of their programs to a greater degree than federal administrators since state governments see these programs as optional and costly in terms of providing for 50 percent of their budgets. Therefore, the higher values of $P$ and $V$ for state programs may reflect the fact that they wish to present to the state legislature the impression that a substantial amount of work is 
conducted by the state job safety agency. The federal program, though, is not optional and serves to impose different incentives on federal administrators. One would not expect to find the same result for penalties $F_{1}$ and $F_{2}$ since this would represent higher monetary costs to firms under state programming. As discussed in the model of state programming, this result is not in the interest of states which operate their own programs.

\subsection{Test of hypothesis 2: Differences between variances}

Hypothesis 2 is that the characteristics of state enforcement programs are more variable than those of federal programs. Tests of differences between the variances of the enforcement parameters are used to compare the variability of the enforcement programs of the two jurisdictions. Table 2 displays the test statistics for the null hypothesis that there exists no significant differences between the variances of enforcement parameters in the two jurisdictions between fiscal years 1975 to 1977 . The numbers displayed for variances, $\sigma^{2}$, are $F$-statistics. Tests of differences between variances indicate that there exist significant differences for all parameters. Moreover, there exists no exception to the rule that state jurisdiction displays the higher variance.

Tests of differences between variances strongly support the hypotheses that the characteristics of state enforcement programs are more variable than those of federal programs. This indicates that state programs provide less uniformity in parameter employment relative to federal programs. In this sense, the states which operate their own programs offer firms greater variety than those states subject to federal regulation. This result is expected since state programs are operated by 21 independent regulatory agencies while

Table 2. Tests of differences between means and variances of parameters between state and federal jurisdiction

\begin{tabular}{lcccc}
\hline Parameter & & 1975 & 1976 & 1977 \\
\hline Probability of inspection, $P$ & $\mu$ & $3.48^{*}$ & $3.96^{*}$ & $4.00^{*}$ \\
& $\sigma^{2}$ & $221.21^{*}$ & $47.30^{*}$ & $79.07^{*}$ \\
Average serious fine, $F_{1}$ & $\mu$ & $2.15^{* *}$ & .16 & $1.04^{*}$ \\
& $\sigma^{2}$ & $215.05^{*}$ & $2.17^{*}$ & $3.63^{*}$ \\
Average nonserious fine, $F_{2}$ & $\mu$ & 1.30 & .33 & 1.56 \\
& $\sigma^{2}$ & $1000.14^{*}$ & $15.18^{*}$ & $42.72^{*}$ \\
Violations per firm, $V$ & $\mu$ & $2.93^{*}$ & $2.70^{*}$ & $4.53^{*}$ \\
& $\sigma^{2}$ & $10.51^{*}$ & $3.27^{*}$ & $6.02^{*}$ \\
\hline
\end{tabular}

Note. Absence of an asterisk indicates that the coefficient is insignificant from zero.

* denotes significance at .01 level.

** denotes significance at .05 level. 
federal programs are operated by one federal agency. The policy implication is that it does matter to firms which government unit regulates them when we consider variability of enforcement.

\subsection{Test of hypothesis 3: Rank correlation}

Tests of rank correlation determine whether or not there exists significant degrees of rank correlation between the values of enforcement parameters for each jurisdiction. Spearman's test of rank correlation is applied to the data. ${ }^{13}$ Table 3 displays the estimated coefficients of rank correlation for the null hypothesis that the employment of enforcement parameters is not rank correlated between adjoining years. There exists no exception to the rule that there exists positive and significant rank correlation between the employment of parameters in adjoining years. In six of the eight cases the correlation is higher under state programming. The two cases where the correlation is higher under federal programming are for penalty parameters.

Tests of rank correlation supports the hypothesis that state programs offer firms a more stable regulatory environment over time and therefore less uncertainty than do federal programs. This implies that the ranking of

Table 3. Rank correlation coefficients between parameters for state and federal jurisdictions in adjoining years

\begin{tabular}{lcrc}
\hline Parameter & Adjoining years & State & Federal \\
\hline Probability of inspection, $P$ & $1975+1976$ & $.84^{*}$ & $.57^{*}$ \\
& $1976+1977$ & $(6.71)$ & $(3.73)$ \\
& & $.77^{*}$ & $.70^{*}$ \\
Average serious fine, $F_{1}$ & $1975+1976$ & $(5.27)$ & $(5.25)$ \\
& & $.49^{*}$ & $.52^{*}$ \\
& $1976+1977$ & $(3.02)$ & $(3.27)$ \\
Average nonserious fine, $F_{2}$ & & $.75^{*}$ & $.33^{* *}$ \\
& $1975+1976$ & $(4.87)$ & $(2.20)$ \\
& $1976+1977$ & $.38^{* *}$ & $.43^{* *}$ \\
Violations per firm, $V$ & & $(2.25)$ & $(2.48)$ \\
& & $.71^{*}$ & $.48^{* *}$ \\
& $1975+1976$ & $(4.39)$ & $(2.53)$ \\
& $1976+1977$ & $.85^{*}$ & $.55^{*}$ \\
& & $.6 .72)$ & $(2.85)$ \\
& & $.90^{*}$ & $.72^{*}$ \\
\end{tabular}

* denotes significance at .01 level

** denotes significance at .05 level.

$t$-values in parentheses. 
stringency among regulatory programs by states is more stable under state programming. Therefore, states, by electing to operate their own programs, may decrease part of the costs of regulation to firms. The federal program, on the other hand, has operated under four different administrators, each of whom had attempted to change the focus of the enforcement program. In this sense the federal program produces greater uncertainty costs than state programs.

\section{Conclusion}

The public policy implication that is drawn from these tests is that it matters to firms which government unit regulates them. While there exists no evidence to indicate that state programs exert lower monetary costs of noncompliance on firms, there does exist evidence which suggests that state programming offers higher nonmonetary enforcement activity, lower uncertainty costs, and greater variety in regulatory environments than does federal programming. For these reasons some states may find it beneficial to operate their own job safety programs. The model of state programming suggests at least one avenue for regulatory reform. This would be to allow states to operate their own programs in all regulatory areas as long as they operate programs which are as effective as their federal counterparts. Then state programming offers firms a means of lowering their regulatory costs in terms of lowering uncertainty while providing at least the average level of enforcement as the federal program.

\section{NOTES}

1. Occupational Safety and Health Act (1970).

2. See Wood (1976) for a discussion of the status of state job safety regulation prior to 1970.

3. Occupational Safety and Health Act (1970), Sec. 18.(c)(2).

4. Program and Policy Series (1975).

5. Office of State Programs (1977).

6. This is consistent with the hypothesis in Tiebout (1956) that neighboring localities compete with each other for residents. For example, see Oates (1969) for a discussion of municipalities competing for residents through tax packages.

7. Another possible benefit, as felt by state governments, may be that it allows state bureaucracies to grown as they take over safety regulation from OSHA.

8. An alternative explanation for why some states operate their own programs is that they wish to provide workers with greater workplace protection than would be provided by OSHA. Higher rates of inspection and penalties relative to the federal program would be evidence of this rationale.

9. Data is obtained from Bureau of Labor Statistics (1976).

10. The lack of data on occupational risk for later years necessarily confines this analysis.

11. The enforcement data is obtained from Office of Management Data and Statistical Analysis (1977). The number of firms in each state is obtained from Office of the President (1973). 
12. Occupational Safety and Health Act (1970), Sec. 17.

13. See Steele and Torrie (1960) for a description of this test.

\section{REFERENCES}

Bureau of Labor Statistics. (1979). State data on occupational injuries and illnesses in 1976. U.S. Department of Labor, Report 576.

Oates, W. (1969). The effect of property taxes and local public spending on property values: An empirical study of tax capitalization and the Tiebout hypothesis. Journal of Political Economy, No. 6.

Occupational Safety and Health Act. Public Law 91-596. 91st Congress. S. 2193, 29 December 1970.

Office of Management Data and Statistical Analysis. (1977). 1-CAR and SPO2 Reports. Occupational Safety and Health Administration.

Office of State Programs. (1977). Status of state plans. Occupational Safety and Health Administration.

Office of the President. (1973). President's report on occupational safety and Health.

Program and Policy Series. (1975). How OSHA monitors state plans. Occupational safety and Health Administration.

Steele, R. G. D., and Torrie, J. H. (1960). Principles and procedures of statistics. New York: McGraw-Hill.

Tiebout, C. M. (1956). A pure theory of local expenditures. Journal of Political Economy 63(October).

Wood, N. J. (1976). Environmental law and occupational health. Labor Law Journal 27(March). 